\title{
Long Term analysis of submarine transmission grid extensions between the Greek islands and the mainland
}

\author{
Eleni Zafeiratou \\ University College London, \\ Energy Institute \\ London, United Kingdom \\ e.zafeiratou@ucl.ac.uk
}

\author{
Catalina Spataru \\ University College London, \\ Energy Institute \\ London, United Kingdom \\ c.spataru@ucl.ac.uk
}

\begin{abstract}
Interconnections' infrastructure is considered fundamental to implement the common rules for the internal electricity market according to 2009/72/EU. Greece currently consists of 29 non-interconnected island systems, experiencing frequent forced outages and high generation costs. A number of interconnection plans are in the pipeline between the Greek islands in the Aegean Sea archipelago and the Greek bulk continental grid. This paper investigates interconnection scenarios and their impact in terms of security of supply, costs and renewable energy integration into the system. PLEXOS ${ }^{\circledR}$ Simulation Software by Energy Exemplar is used to simulate the Greek electricity system. The results show a twofold growth of renewables share between 2020 and 2040 while electricity generation costs recorded on the non-interconnected islands mirror continental costs following the grid extensions. Loss of load probability and unserved energy are eliminated, whilst greenhouse gas emissions are reduced by 73\% (vs 1990) in 2040.
\end{abstract}

Keywords - submarine interconnections, isolated power systems, renewable energy, transmission extensions, long term scenario analysis, mixed integer linear programming

\section{NOMENCLATURE}

c unit

Cc capacity outage (MW)

$\mathrm{ER}_{\mathrm{i}} \quad$ forecasting error rate

$\mathrm{Fd}_{(\mathrm{InCap}-\mathrm{Cc})}$ value of the built load duration curve at demand equal to InCap-Cc

Fy probability that a capacity outage $\mathrm{Cc}$, happens

i type of RES technology

InCap installed capacity for the region

LOLP loss of load probability

Lt load attributed to touristic activities

Lp load attributed to local population activities

Lpf load participation factor

$\mathrm{Wf}_{(\mathrm{p})}$ population weight factor

$\mathrm{Wf}_{(\mathrm{t})} \quad$ tourism weight factor

\section{INTRODUCTION}

\section{A. Motivation and Background}

In the context of an integrated electricity market, the European Commission has adopted the 2030 electricity interconnection target of $15 \%$ [1], as it has become commonly accepted that the energy transition cannot be attained without adjusting the infrastructure to facilitate larger amounts of clean energy. The Greek power system has the peculiarity of comprising several non-interconnected islands (NII) systems. NII phase several complications related to the security of supply, limited integration of renewable energy resources
(RES) and high generation costs ranging between $80 € / \mathrm{MWh}$ and $400 € / \mathrm{MWh}$ [2], in contrast to the average continental marginal price of $\approx 50 € / \mathrm{MWh}$ [3]. As of 2020 , the Greek islands will have to comply with the Directives 2010/75/EU and 2015/2193/EU, incumbering oil-fired local power generation. To address security of supply issues and reduce generation costs, submarine grid extensions are planned to be implemented throughout the upcoming decades, to facilitate a regional super-grid among the Greek islands and the mainland, which could be potentially expanded into third countries

\section{B. Relevant Literature}

In [4] the feasibility of interconnecting the Greek islands to the mainland grid for the period 2009-2020 was analysed, using a dynamic, deterministic, long-term energy model which belongs to the Mixed Integer Linear Programming (MILP) family. The islands and the respective interconnection capacity are clustered in groups, while an annual time step is adopted. The results proved that RES penetration is possible to reach $56 \%$ at national level, at the same order of magnitude with the results presented in section IV, however considering a different projection horizon. Such an alignment determines the market's eagerness to invest in RES acceleration with the prerequisite of building the necessary infrastructure. A MILP model is also presented in [5] with a mid-term annual horizon this time and an hourly scheduling period which assesses the feasibility of the interconnection of Crete island. The results indicate the benefits from the services provided by the hydroelectric units, in parallel with renewables gradual increase in Crete, while a similar conclusion is drawn in the analysis conducted for Crete in [6]. The economic interest of interconnecting the island of Lesvos through an integrated theoretical model is highlighted in [7]. In particular, the authors argue that the full economic potential of future interconnections is realised only in parallel with rapid RES development. This is reflected in the Levelised Cost of Energy (LCOE) of the interconnection project which could be reduced by $40 \%$ if coupled by utility scale wind deployment.

\section{Contribution and Organisation}

This paper builds on previous studies while investigating customised, novel energy scenarios, through an overarching, dynamic, cost-optimisation approach combined with realistic operating and design conditions. It blends existing and future submarine infrastructure along with a wider geographical scope compared to previous studies. At the same time, it pinpoints the non-interconnected region down to the island 
level, simulated with hourly temporal granularity. Three main scenarios have been deployed: 1) the Autonomous Scenario 1 with increased RES share and energy storage deployment, 2) the Autonomous Scenario 2 with lower RES share and no energy storage demonstrated, assuming a future with less ambitious targets and techno-economic constraints 3) the Interconnected Scenario. In addition, an in-depth investigation of key techno-economic indicators has been performed.

\section{OVERVIEW OF THE SUBMARINE GRID EXTENSION PlANS}

The Greek non-interconnected islands are located mainly in the Aegean Sea. Currently they consist of 29 noninterconnected systems comprising 47 islands, split in three main regions: North Aegean, South Aegean including Dodecanese and Cycladic islands and Crete. At last, Skyros which belongs to the Sporades islands complex is integrated in the analysis. The Independent Power Transmission Operator has proposed the following interconnections as illustrated in Fig. 1.

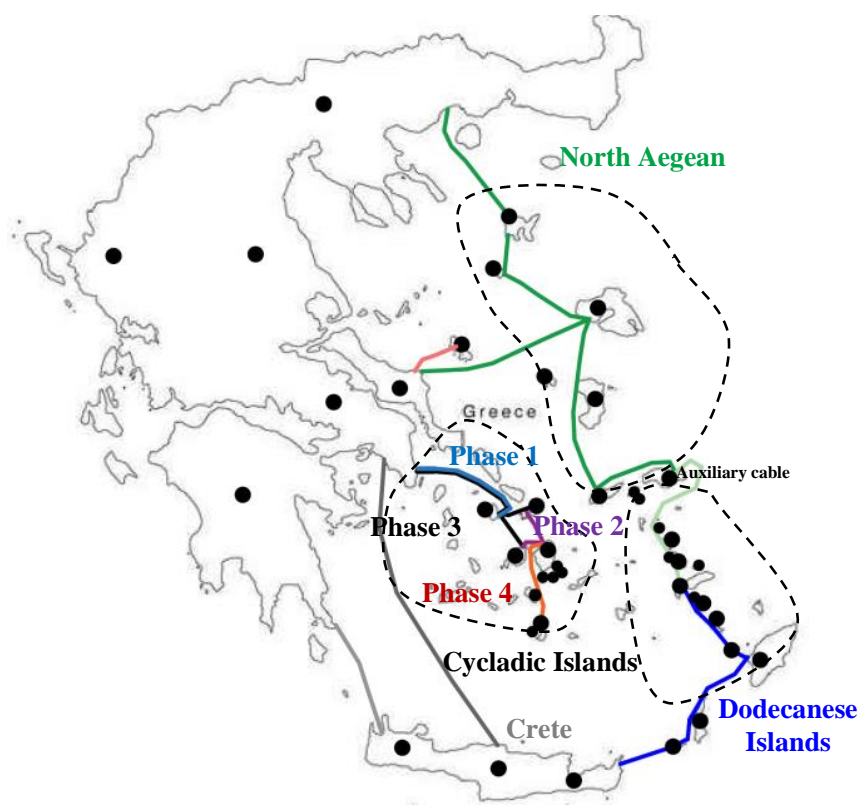

Fig. 1. Map of the Greek islands grid extensions plan

Cycladic Islands - Phase I \& II completed in 2018, includes the AC interconnection of Syros (200 MVA) with the Greek mainland and the interconnection of Syros with Paros, Mykonos (140 MVA) and Tinos islands (200 MVA). Phase II, includes the expansion of the cable to Naxos and Mykonos islands (140 MVA) formulating a loop among Syros, Paros, Naxos, Mykonos to fulfil the N-1 criterion. Phase III (2024), will incorporate a second cable from Central Greece to Syros. The expansion of the submarine cable from Paros to Thera is estimated to be implemented in 2022 .

Crete Island - Phase I to be completed by 2021, aims in reducing local power generation and interconnects Crete with Peloponnese) through AC $2 * 150 \mathrm{kV}, 200$ MVA cables. Phase II, estimated to be completed by 2024 proposes the interconnection of Crete with Attica (DC cables, 2*500 MW). The second cable will progressively reduce the local oil-fired generation and will facilitate the export of RES generation surplus installed on the island to the continental grid [6], [8].
North Aegean Islands - The scheduled year was originally 2030, nonetheless the project will have to anticipate its implementation to ensure security of supply due to the horizontal local power generation restrictions, to be imposed as of 2030. During Phase I, the interconnection between Lesvos and Chios islands as well as between Chios and the continental National Grid System (NGS) (DC 2*350 MW) is assumed to take place in 2027. Chios and Lesvos will be interconnected with a double circuit DC $2 * 250$ MW. Phase II includes the interconnection of Chios with Ikaria and Samos islands through AC 2*140 MVA cables in 2028. Phase III proposes the interconnection of Lemnos island to Lesvos via an intermediate substation in Agios Efstratios (AC 2*140 MVA) and finally to Northern Greece through DC $2 * 250 \mathrm{MW}$ cables. Phase IV proposes the use of an auxiliary cable to interconnect Kos island (Dodecanese region) with Samos through AC $2 * 140$ MVA cables.

Dodecanese Islands - Phase I (2028) of this project proposes the interconnection of Rhodes with Kos-Kalymnos power system via Telos and Nisyros. Following the immersion of the cable, Rhodes power station will supply power to the rest of the islands. In addition, Nisyros' geothermal power station $(\approx 40 \mathrm{MW})$ could cover the islands' baseload power requirements. Phase II (2030) proposes the interconnection of Dodecanese islands with Crete with AC $2 * 280$ MVA cables. The interconnection route will include the following terminals: Crete, Kasos, Karpathos and Rhodes.

\section{METHODOLOGICAL APPROACH}

\section{A. Electricity system modelling approach}

A model representing the Greek electricity system was built in PLEXOS, an electricity market software tool for planning and dispatching used by energy regulators, operators, and academic institutions worldwide. PLEXOS performs generation and transmission capacity expansion and dispatch from a central planning, Long Term (LT) perspective using MILP. The LT module of PLEXOS was used to simulate the islands generation capacity, interconnections current state, future extensions and retirements. The objective function of LT plan seeks to minimize the net present value of build costs including fixed operations and maintenance costs plus production costs [6].

In the second phase, the results were input in the Medium Term (MT) and ultimately in the Short Term (ST) module, using Mixed-Integer Programming at full chronological optimization. The ST emulations were performed for weekly horizons using an hourly time step. The results of the LT simulation have been presented focusing on the long-term (2020-2040) impact of the interconnections in the Greek electricity system.

\section{B. Spatio-temporal representation of the Greek Generation and Transmission System}

The spatial representation of the continental power grid in the model is defined by six nodes under a single electrical region representing the $\mathrm{HV}$ national grid system consisting of $150 \mathrm{kV}$ and $400 \mathrm{kV}$ lines. The Greek islands were simulated in higher resolution with one node representing a geographical island and each electrical (interconnected) system represented by a 'region'. Attributable to the large size of Crete island, it is represented with three interconnected nodes and a single 
region as illustrated in Fig. 1. The existing (25) MV subsea cables among the islands as well as the existing and future HV interconnections were introduced in the model alongside their techno-economic characteristics (current AC/DC, capacity, reactance, resistance, installation and maintenance costs).

A quarterly load duration curve with 12 blocks and an hourly timestep have been used. The hourly load profile of each system was input in the model for the reference year 2016. A load participation factor was assigned to each 'node' (island) which was calculated taking into consideration the load attributed to activities of the local population and tourism. Loads exciding $\approx 15 \%$ of the average hourly load between May and September (Summer period) as well as December (Christmas period) were considered as loads generated by touristic activities and the rest was linked to local population activities. The tourism weight factor was estimated considering the accommodation facilities located in each island while the equivalent factor for the local population was based on the local population. The Load Participation factor for each island was calculated according to (1).

$$
L p f=L p^{*} W f_{(p)}+L t^{*} W f_{(t)}
$$

Five annual hourly wind and solar hourly profiles were inserted in the model as samples to reflect the wind and solar stochasticity for each node modelled. The LT Plan ran for a single time incorporating all samples into a stochastic optimization and yielded a single optimal set of capacity expansion decisions and one generation solution.

\section{Techno-economic assumptions}

For each electrical region (electrical system) the respective local thermal generation capacity (diesel light fuel or mazut) was modelled on a unit-by-unit basis. The existing local renewable generation was simulated maintaining the same approach for RES except for photovoltaics (PVs) with capacity $<0.2 \mathrm{MW}$ which were grouped. In the present analysis the following resources have been considered: wind (onshore and offshore), solar, solar thermal, bioenergy, geothermal and hydropower (with storage, pumped and runoff-river). The assumptions related to the variable generation costs and respectively the feed-in scheme for the Greek mainland and the islands separately derive from [9]-[11]. Current build costs as well as projections for various technologies have been obtained from [10]-[13]. Build costs have been granulated at an annual level from 2020 to 2040 and have been differentiated between islands and the NGS to reflect the economy of scale discrepancies' as usually multi MW utility scale projects take place in the continental part of Greece. To secure the stability of the local power network, integration of new RES to the islands at the autonomous state is limited by the annual constraint of: installed RES capacity for year (n) is less or equal to $30 \%$ of the forecasted annual peak demand for year $(n+1)$.

Fuel prices and taxes for years 2016/2017 are presented in TABLE I. Conventional fuel price projections derive from the IEA 'New Policies Scenario' [17]. [18]. Carbon emissions prices were estimated at circa $6 € /$ tn (2015 prices) [19] while future projections were obtained from [20].

TABLE I. CONVETIONAL Fuels and TAXes [14], [15] , [16]

\begin{tabular}{|c|c|c|c|c|}
\hline Cost Item & Unit & $\begin{array}{l}\text { Natural } \\
\text { Gas }\end{array}$ & $\begin{array}{l}\text { Heavy Fuel } \\
\text { Oill }\end{array}$ & Diesel \\
\hline Price & \multirow[t]{2}{*}{$€ / G J$} & 5.5 & 6.6 & 14 \\
\hline Tax & & 0 & 0.4 & 9.7 \\
\hline
\end{tabular}

\section{Ancilliary Services \& Reliability}

Ancillary services provided on the island from local generation have been split into three different types of reserve provision: regulation (frequency keeping) capability, fast response or spinning reserve (for various timeframes such as 6-60 seconds, or several minutes), non-spinning (or replacement) reserves. Regulation and fast response spinning and non-spinning reserves are provided by: steam generators and gas turbines contributing with $10 \%$ and $15 \%$ of their net capacity respectively, combined cycle gas turbines (CCGT) and internal combustion engines (ICE) with $20 \%$. Furthermore, capacity that is retired is preserved as a cold reserve and contributes to the replacement provision (reflecting 10-15\% of the annual peak load). Requirements for fast response and regulation reserves have been set to the minimum among: a) $10 \%$ of the decade peak load (20202030, 2031-2040) b) a contingency generator: the largest local thermal generator and c) regional load risk of $8-12 \%$. In addition, a set of constraints were inserted in the model to reflect the intermittency of RES which ensures that the committed reserved capacity is always higher than a certain forecasting error rate $\left(\mathrm{ER}_{\mathrm{i}}\right)$, reflecting hourly RES intermittency multiplied by the forecasted hourly RES production. In the Interconnection Scenario, the capacity reserve sharing option has been activated amongst the interconnected regions.

The reliability of the system has been determined by the PASA (Projected Assessment of System Adequacy) module. The scheduled (maintenance) and forced outages were inserted in the model using statistics from 2015 and 2016 [21], [22]. In the context of this study, the reliability of the system is reflected in the unserved energy and Loss of Load Probability (LOLP). The model iterates through all units in each region, accumulating the unit outages and calculating their respective probabilities. The load duration curve (LDC) from the peak PASA region load derives from these values entered into a 'capacity outage probability table'. This modified curve is then used to obtain the LOLP based on the following convolution method:

$$
\begin{aligned}
\mathrm{LOLP} & =\sum_{(c)} \mathrm{f}_{\mathrm{y}} \cdot \mathrm{C}_{\mathrm{c}} \cdot \mathrm{F}_{\mathrm{d}}\left(\mathrm{InCap}-\mathrm{C}_{\mathrm{c}}\right) \\
\text { for } c & =1 \text { to } N
\end{aligned}
$$

\section{IV.RESULTS}

\section{A. Renewable Energy Share}

Renewable energy development is equally a key priority for the long-term energy strategy in the European Union (EU) but also a national target. In 2020, according to Fig. 2, trivial variations are recorded among the scenarios as the existing infrastructure is marginally affected. Scenario 1 is the front runner in RES share in 2030. The system is responding to the thermal generation restrictions imposed by Directives 2010/75/EU and 2015/2193/EU while significant capacity of energy storage is added to the system to facilitate intermittent RES acceleration. The two directives enforce as of 2020, oilfired steam and gas turbines restrictions to 1,500 and 500 operational hours per year. From 2030, it decreases to 500 hours horizontally, including ICE. In 2040 however, the Interconnection Scenario takes the lead in RES generation on islands with renewables exceeding $136 \%$ of the local load demand. Scenario 2, records the lowest levels due to RES integration constraints in small isolated grids and no 
regulation to facilitate off-shore deployment. RES development in the mainland is slightly affected, whereas multi MW wind offshore projects compete with equivalent in the mainland. Under Scenario 1, the RES share in the continental grid is growing independently, receiving a boost under the 2030 EU targets. The landscape in 2040 is reverted as the Scenario 1 reaches a saturation level of wind and solar penetration coupled with hydro and solar thermal storage; particular islands such as Crete and Chios showcase intermittent RES penetration which exceeds $47 \%$ of the annual power generation. In contrast, by 2040, the integrated electricity system incorporating the continental network and the islands, deploys its full potential and RES generation increases across the country.

EU and National targets are achieved in 2020 across all scenarios (islands' participation in the total RES share is limited between $5 \%$ and $11 \%$ ). On the contrary, in 2030 only Scenario 1 is close to achieve the ambitious targets (with 38.2 $\mathrm{TWh}$ ), as in the Interconnection Scenario (36.6 TWh) the mass RES deployment on islands is materialized following that milestone year, signaling for a relatively slower RES deployment in the mainland, competing with higher capacity factors recorded in the islanding region. In 2040, with the ultimate goal to abolish carbon emissions from the energy sector by 2050 , a target of $70 \%$ RES share in the electricity mix is assumed. Greece will achieve these commitments only through the necessary infrastructure to export RES surplus from the islands to the mainland. The Interconnection Scenario shows that islands participation in the national RES mix could reach up to $21 \%$ share by 2040 (51.5 TWh) and exceed $30 \%$ by 2050 , while the system is benefiting from the increased efficiencies due to the higher RES potential in the area compared to the mainland. Interconnections bring down to zero wind energy curtailments on the islands from 1.9\%/year (average 2020-2040) in Scenario 1.

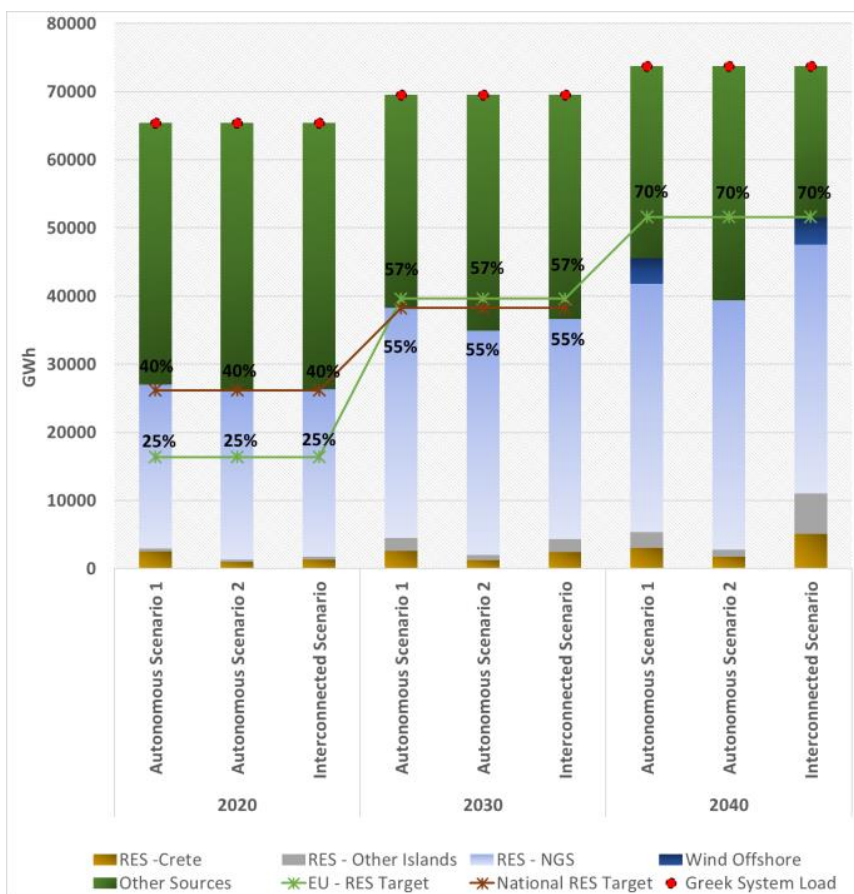

Fig. 2. RES Generation in Autonomous and Interconected Scenarios against EU and National Targets

\section{B. Reliability Indicators (LOLP and Unserved Energy)}

The Loss of Load Probability (LOLP) measuring the probability of demand exceeding the capacity of the system in a given period is presented in Fig. 3, for the three main scenarios as well the Autonomous Scenario assuming no generation restrictions $(B A U)$. This scenario allows to compare the LOLP indicators for the two main pathways: Autonomous and Interconnected, with focus on a normal evolution of the capacity unaffected by generation restrictions. In 2020, several regions present higher LOLP than the acceptable threshold of $0.03 \%$ [8]. By 2030, the risk of power interruptions is increasing mainly in the BAU Autonomous Scenario. In contrast, autonomous scenarios imposed with generation restrictions as of 2030 invest heavily in new generators.

By 2040, the retirement of thermal power generation on the islands and the economic infeasibility of the system to continue investing in new generators with low capacity factors, leads to higher LOLP in Scenario 2 with limited renewable energy development. The Scenario 1 seems to impact Agios Efstratios, Kos-Kalymnos and Thera regions as energy storage deployment in the form of hydropower and solar thermal has limited benefits on those regions. In this case, scenarios with other energy storage systems such as batteries, compressed air energy storage, or hydrogen storage coupled with fuel cells have to be explored. The results show that in the long-run, none of the autonomous scenarios can cover sufficiently peak demand. Alternatives to interconnections, merely for small NII could be showcased by thorough customised design of smart grids teamed with energy storage systems.

In the BAU Autonomous Scenario without restrictions, the analysis showed negligible amounts of unserved demand mainly as an outcome of forced or planned outages (therefore it has not been plotted). In contrast, for Autonomous Scenarios 1 and 2 imposed to generation restrictions by 2030 the inadequacy of the system to meet demand requirements as of that year is evident (Fig. 4). The interconnection scenario records unserved loads of less than $0.01 \%$ of the demand. Nonetheless, the BAU Interconnection Scenario scheduled to implement the Dodecanese interconnection following 2030 would also cause unserved loads to the Dodecanese islands which could be eliminated by accelerating the immersion of the cables in the region as proposed under this study.

\section{Electricity Generation \& Total Costs}

Electricity price in PLEXOS per region is the average load-weighted price paid by loads. According to Fig. 5, the cost-optimum option considering the electricity generation costs is the islands' interconnection. Under the interconnection scenario, the prices remain mostly within the range of 20-100 €/MWh. Under Autonomous Scenario 1 and mainly Scenario 2 relying primarily on diesel and mazut as primary energy source, prices exceed $600 € / \mathrm{MWh}$ and reach the value of lost load (energy shortage price) which has been set at 3,000 €/MWh across all regions. This is an outcome of the large volumes of unserved demand that the system fails to supply due to power generation restrictions. The Interconnection scenario with total generation and fixed costs within the 20-year horizon equal to $158.3 €$ billion is considered an investment intensive scenario. 


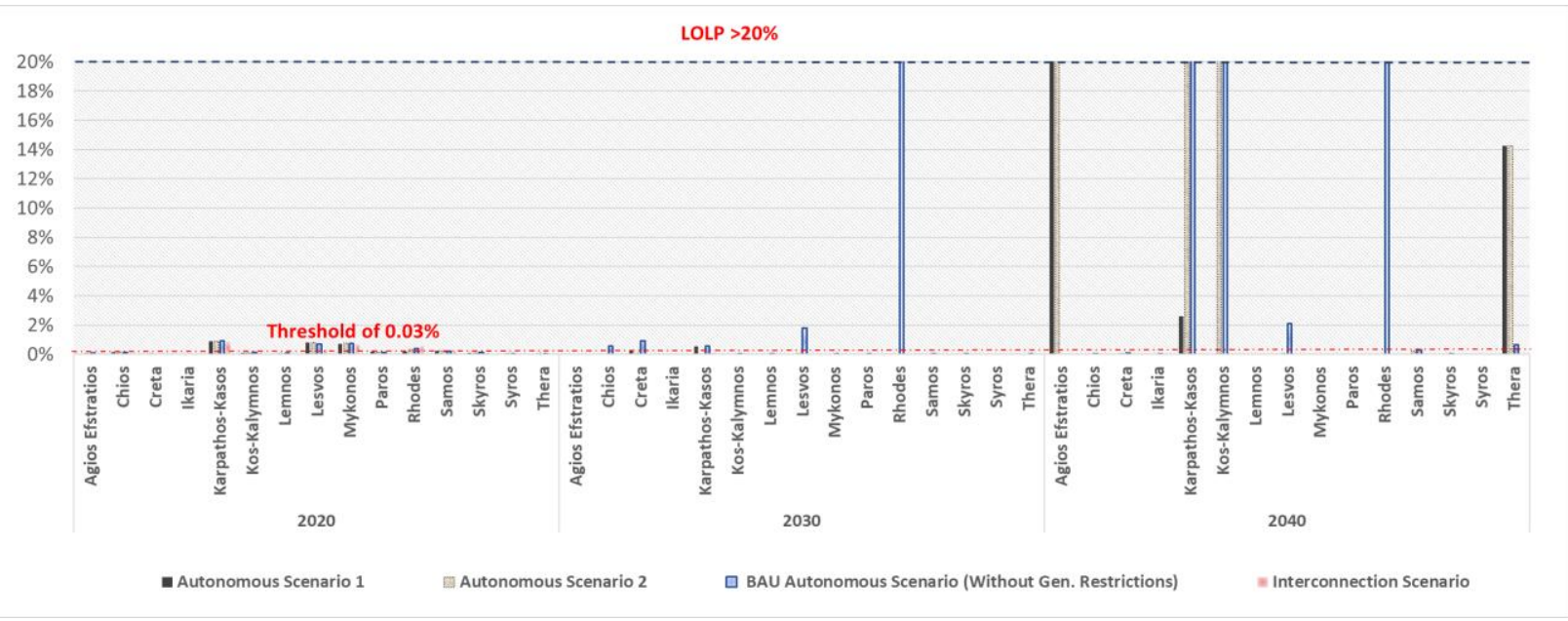

Fig. 3. Loss of Load Probability

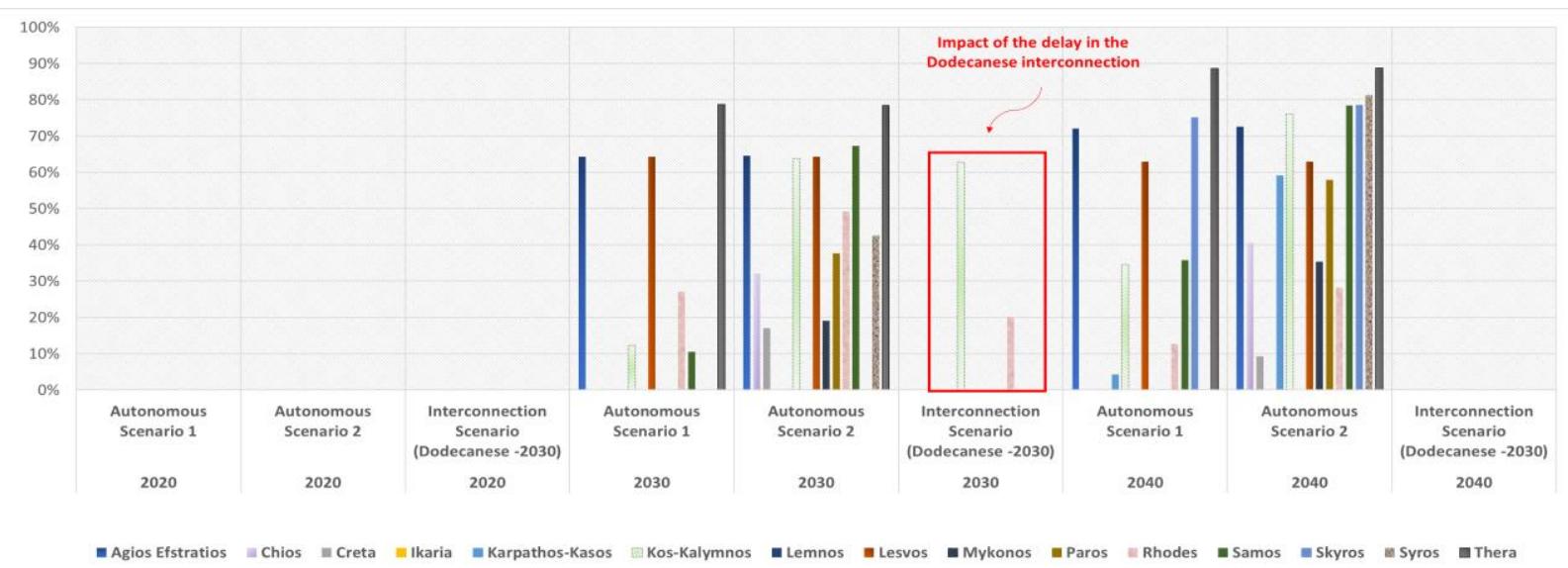

Fig. 4. Unserved energy reflected as percentage (\%) of the annual load

Under the assumption of no generation restrictions both the Interconnection and Autonomous Scenarios reach $159 €$ billion (2020-2040). However, by adopting the 'New Policies' fuel price scenario, with extra low Sulphur requirements the direct economic savings from the interconnection could exceed $5.8 €$ billion assuming no generation restrictions. The Autonomous Scenarios 1 and 2 demonstrate low total costs $145.5 €$ billion and $147 €$ billion respectively, however, without monetizing the socioeconomic impact of multiple power interruptions recorded, therefore they are not directly comparable with the Interconnection Scenario.

\section{Greenhouse Gas Emissions}

Greenhouse Gas (GHG) Emissions reflected in $\mathrm{CO}_{2}$ equivalent emissions are dropping, driven by RES growth. The impact of islands' emissions on the Greek system is mostly evident after 2035 under full RES deployment, where $16 \%$ deviation is observed between the Autonomous Scenario 2 and the Interconnection Scenario. Fig. 6 shows that the interconnection scenarios demonstrate the most sustainable options across the decades.

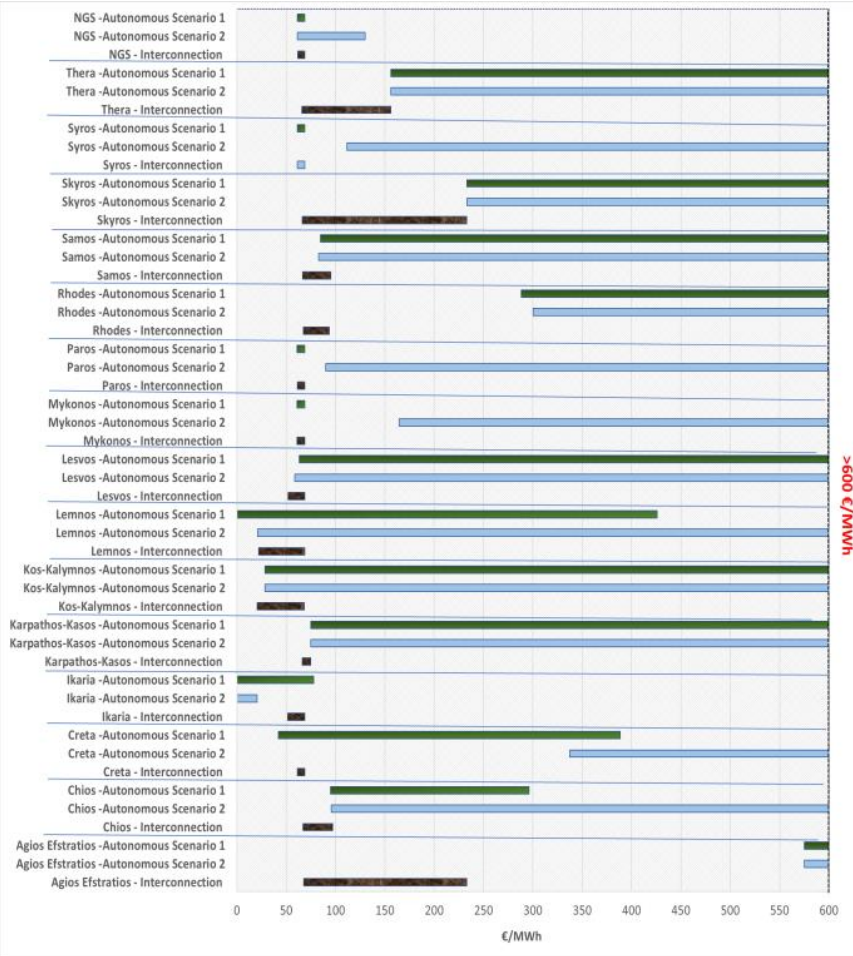

Fig. 5. Electricity Prices per region 


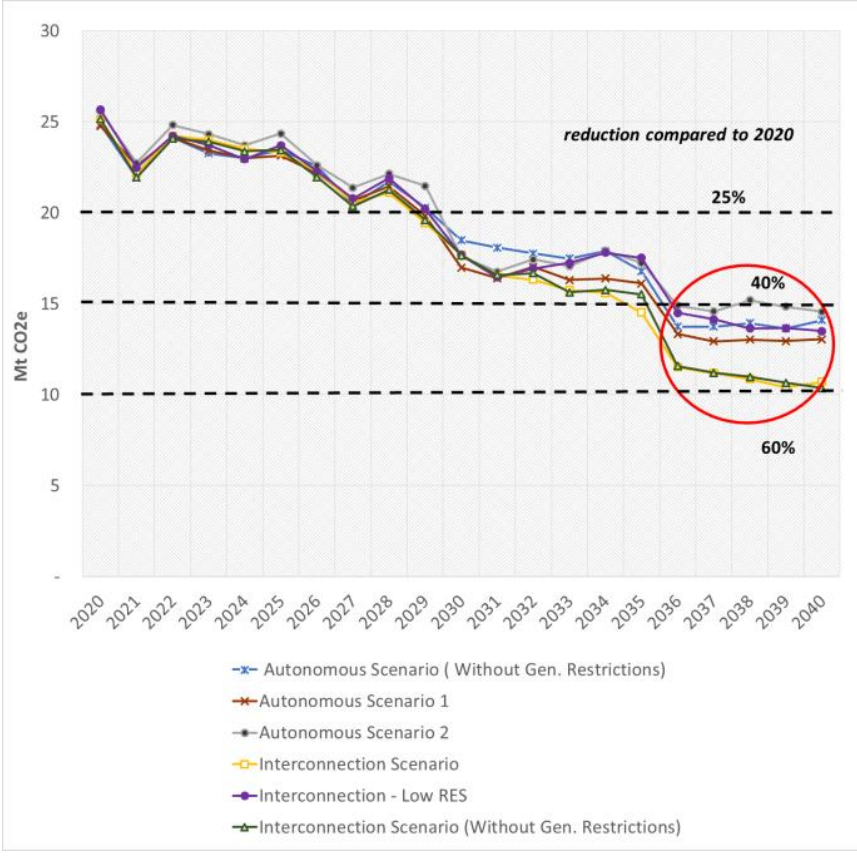

Fig. 6. Greenhouse gas emissions trends for the Greek Electricity System

In particular, the Interconnection Scenario with high RES development attains a decrease of $57 \%$ in total GHG emissions by 2040 compared to 2020 and $73 \%$ compared to the 1990, set as baseline year by the United Nations. In contrast, the Interconnection Scenario with low RES development records a decrease of $47 \%$, implying that a sustainable energy strategy for the islands following their interconnections could stimulate further emissions reductions by $10 \%$. The Autonomous Scenario 2, records the highest emissions' levels as it does not foresee wind offshore largescale deployment, exceeding the Interconnection Scenario by more than $35 \mathrm{MtCO} 2 \mathrm{e}$ in aggregated terms between 2020 and 2040.

\section{CONCLUSIONS}

This paper presents a long-term scenario analysis of the electricity sector in the non-interconnected islanding region with the use of PLEXOS $®$ Simulation Software. The results show that future interconnections could demonstrate as an economically feasible and environmentally sustainable solution. Power generation costs are drastically reduced from $200-600 € / \mathrm{MWh}$ to $20-100 € / \mathrm{MWh}$. Interconnections are capital intensive investments but in the long run they bring down total costs by $1-5.8 €$ billion compared to the BAU case. In parallel, interconnections support high renewable energy deployment, reaching 51.5 TWh by 2040 while eliminating wind and solar curtailments. As a consequence, carbon emissions are reduced by $60 \%$ in the Interconnection Scenario. Autonomous Scenario 2, cannot facilitate a sustainable option for Greece as it doesn't meet the security of supply criterion. Autonomous Scenario 1, in spite of the considerable RES boost, records sizable amounts of unserved energy which prohibit its applicability. Future work will comprise simulations incorporating battery storage systems through battery electric vehicles as well as a demand response strategy for the islands following their interconnection with the national grid system.

\section{REFERENCES}

[1] European Commission, "Energy Union - the year of engagement," 2017. [Online]. Available: http://europa.eu/rapid/press-release_IP-174725_en.htm. [Accessed: 05-Dec-2017].

[2] Hellenic Distribution Network Operator, "Statistics reports and monthly reports on Non-Interconnected Islands released," 2017. [Online]. Available: https://www.deddie.gr/en/themata-tou-diaxeiristi-midiasundedemenwn-nisiwn/stoixeia-ekkathariseon-kai-minaion-deltion$\mathrm{mdn} /$ miniaia-deltia-ape-kai-thermikis-paragwgis-sta-mi/2017. [Accessed: 05-Aug-2017].

[3] Hellenic Electricity Market Operator, "Electricity Market Exchange Monthly Report," 2017. [Online]. Available: http://www.lagie.gr/fileadmin/groups/EDRETH/DAS_Monthly_Reports /201704_DAS_Monthly_Report.pdf. [Accessed: 23-Sep-2018].

[4] P. N. Georgiou, G. Mavrotas, and D. Diakoulaki, "The effect of islands ' interconnection to the mainland system on the development of renewable energy sources in the Greek power sector," Renew. Sustain. Energy Rev., vol. 15, no. 6, pp. 2607-2620, 2011.

[5] N. E. Koltsaklis, A. Dagoumas, G. Tsioni, and \#Christos Dikaiakos, "A mid-term, market-based power systems planning model," Appl. Energy, no. October, 2016.

[6] E. Zafeiratou and C. Spataru, "Sustainable island power system Scenario analysis for Crete under the energy trilemma index is," Sustain. Cities Soc., vol. 41, no. January, pp. 378-391, 2018.

[7] M. Kapsali, J. K. Kaldellis, and J. S. Anagnostopoulos, "Investigating the techno-economic perspectives of high wind energy production in remote vs interconnected island networks," Appl. Energy, vol. 173, pp. 238-254, 2016.

[8] J. Kabouris, "Interconnection of Crete," 2016. [Online]. Available: http://www.crete.gov.gr/attachments/article/10001/A $\triangle$ MHE_KАМПОY PH $\Sigma$.pdf. [Accessed: 12-Jan-2017].

[9] Hellenic Republic, "Law 4254 (FEK A' 85/07-04-2014) Measures for the support and development of Greek economy in the framework of applying Law 4046/2012,” 2014. [Online]. Available: https:// www.taxheaven.gr/laws/law/index/law/588. [Accessed: 15-Mar-2017].

[10] International Renewable Energy Agency (IRENA), Power Generation Costs in 2017. 2017.

[11] John Hensley, "Wind Power Costs Could See Another 50\% Reduction by 2030," EcoWatch, 2017. [Online]. Available: Wind Power Costs Could See Another 50\%25 Reduction by 2030. [Accessed: 16-Apr2018].

[12] International Renewable Energy Agency (IRENA), "Concentrating Solar Power," no. January, 2013.

[13] REN21, "Renewables 2016 Global Status Report," 2016. [Online]. Available: http://www.ren21.net/wpcontent/uploads/2016/06/GSR_2016_Full_Report.pdf. [Accessed: 17May-2017]

[14] YCHARTS, “European Union Natural Gas Import Price,” 2018. [Online]. Available: https://ycharts.com/ indicators/europe_natural_gas_price. [Accessed: 01-Feb-2018].

[15] U.S. Energy Information Administration, "Spot Prices for Crude Oil and Petroleum Products," 2018. [Online]. Available: https:// www.eia.gov/dnav/pet/pet_pri_spt_s1_d.htm. [Accessed: 31-Jan-2018].

[16] Index Mundi, "New York Harbor Ultra-Low Sulfur No 2 Diesel Spot Price," 2018. [Online]. Available:

https://www.indexmundi.com/commodities/?commodity=diesel\&month $\mathrm{s}=60$ \&currency=eur. [Accessed: 31-Jan-2018].

[17] IEA (International Energy Agency), World Energy Outlook. 2017.

[18] Hellenic Republic, "Law 3828 - Regulations in the Tax Regime of Oil Products Article 1. Consumption Tax of Oil Products," 2010. [Online]. Available: https://www.taxheaven.gr/laws/law/index/law/186. [Accessed: 03-Feb-2017].

[19] Hellenic Republic, Ministerial Decision N. 138/2014, FEK 885, Issue B. Greece: Accessed: 05/03/2014, 2014, pp. 13611-13617.

[20] European Commission, "EU Reference Scenario," 2016. [Online]. Available: https://ec.europa.eu/energy/sites/ener/files/documents/20160 713 draft_publication_REF2016_v13.pdf. [Accessed: 03-Apr-2017].

[21] Hellenic Electricity Distribution Network Operator, "Data for Autonomous Power Systems Power stations," 2017. [Online]. Available: https://www.deddie.gr/en. [Accessed: 15-Jun-2017].

[22] Ensto-e, "Principles for determinig the transfer capacities in the Nordic Power Market," 2017. [Online]. Available: https://www.nordpoolspot.com/globalassets/downloadcenter/tso/principles-for-determining-the-transfer-capacities.pdf. [Accessed: 18-Jun-2017]. 